\title{
Renúncia de arrecadação fiscal: subsídios para discussão e formulação de uma política pública ${ }^{1}$
}

\author{
MARIA DE FÁTIMA SILIANSKY DE ANDREAZZI " \\ CARLOS OCTÁVIO OCKÉ-REIS •
}

Este trabalho pretende investigar diversos aspectos relacionados aos incentivos governamentais que permitem o abatimento de parte dos gastos das famílias e empresas com assistência à saúde no imposto de renda. Como tais incentivos são deduzidos da renda tributável das pessoas físicas e do lucro tributável das pessoas jurídicas, a arrecadação fiscal do Estado é forçosamente reduzida. Segundo estimativa da Secretaria da Receita Federal, o valor desta renúncia, considerando as despesas com planos de saúde e os desembolsos diretos com assistência médico-hospitalar, girou em torno de $\mathrm{R} \$ 2,8$ bilhões em 2005. Em um quadro de subfinanciamento crônico do SUS, esta problemática será discutida à luz da eqüidade do financiamento e dos conflitos de interesse evidenciados no setor saúde.

Palavras-chave: renúncia fiscal; financiamento; economia política da saúde; política de saúde.

Recebido em: 24/01/2007.

Aprovado em: 12/06/2007. 


\section{Introdução}

Este trabalho pretende investigar diversos aspectos relacionados aos incentivos governamentais que permitem o abatimento de parte dos gastos das famílias e empresas com assistência à saúde no imposto de renda. Ao serem deduzidos da renda tributável das pessoas físicas e do lucro tributável das pessoas jurídicas, a arrecadação fiscal do Estado é forçosamente reduzida.

Inicialmente, este artigo apresenta na primeira seção a relevância do problema e faz uma revisão dos conceitos de renúncia fiscal. Na seção seguinte, analisam-se as relações dessa política fiscal com a demanda por planos de saúde, tomando como ponto de partida trabalhos de base empírica, ficando patente a falta de consenso na literatura especializada. Essa literatura é basicamente internacional, na medida da não-identificação de estudos similares na literatura nacional. São identificados, na terceira seção, os termos do debate institucional sobre o tema, evidenciados por meio de registros documentais coletados na Internet, acerca das posições de atores sociais relevantes, a partir do ano de 2000. O papel da renúncia fiscal em saúde na polêmica discussão que envolve o tema da eqüidade em saúde no SUS é abordado, com a identificação de conflitos de interesse, nas seções finais do texto.

\section{O problema: a renúncia fiscal e o financiamento da saúde no Brasil}

O Estado brasileiro vem atuando como o principal financiador das ações e serviços do setor saúde. Esta constatação nos força a reconhecer que uma análise do mercado de serviços de saúde não deve menosprezar suas relações financeiras com o Estado. Além do mais, "diversas podem ser as formas de atuação do Estado no campo da saúde [...]. Concessão de subsídios, isenções fiscais ou incentivos à população resultando no barateamento dos custos de atenção à saúde para a população ou para certos segmentos desta" (MÉDICI, 1990, p. 7).

Neste trabalho, abordaremos tão-somente um dos aspectos desse problema, analisando aqueles incentivos governamentais que permitem que parte dos gastos das famílias e empresas com assistência médico-hospitalar seja abatida no imposto de renda. O conceito por nós utilizado é de gasto tributário; de acordo com Villela (1991, p. 2): 
dentro do conceito de gasto tributário, a transferência (implícita) de recursos se dá da seguinte maneira: por um lado, existe o imposto devido pelo contribuinte ao Estado e, por outro, o interesse do governo de prover uma determinada assistência financeira. Assim, ao deixar de arrecadar parte do imposto a ele devido (como resultado de um benefício fiscal), o Estado age como se estivesse neste exato momento realizando um pagamento. Trata-se de um pagamento implícito, isto é, não há um desembolso por parte do governo, mas, mesmo assim, constitui-se em pagamento de fato.

\section{Na mesma linha, segundo documento produzido pela CEPAL/PNUD:}

o conceito de gastos tributários foi usado pela primeira vez [...] em 1967, referindo-se aos dispositivos existentes na legislação do imposto de renda, que não faziam parte da estrutura do imposto, mas que continham deduções, isenções e outros benefícios fiscais [...] esses benefícios constituíam-se em gastos do governo realizados por intermédio da redução da carga tributária, ao invés de um desembolso direto (CEPAL/PNUD, 1991, p. 43).

Alguns manuais de economia do setor público sugerem, ainda, que a renúncia de arrecadação fiscal possui a natureza de um gasto tributário, isto é, uma unidade monetária de imposto não recolhido deve ser computado e identificado enquanto uma unidade de dispêndio direto não efetuado pelo Estado (BIDERMAN; ARVATE, 2005).

O montante da renúncia de arrecadação fiscal (atribuída à parcela dos tributos que o governo deixa de arrecadar) está diretamente relacionada à renda dos indivíduos e das empresas, bem como aos gastos privados em saúde. No Brasil, os itens do gasto passíveis de abatimento fiscal têm variado ao longo do tempo. Segundo levantamento realizado por Almeida (1998), somente após 1990 permitiu-se a inclusão de despesas com planos de saúde, além da assistência ambulatorial e hospitalar pagas diretamente aos prestadores de serviços. Depois da Constituição de 1988 (ano-base de 1989) foram estabelecidos tetos a serem aplicados na renda bruta dos contribuintes, que limitavam as deduções dos gastos com saúde no Imposto de Renda da Pessoa Física (IRPF). Afinal de contas, à época, parecia um subsídio desnecessário para as camadas de maior poder aquisitivo, à medida que o SUS deveria cobrir, em tese, as necessidades básicas de saúde da população. No entanto, a renúncia voltou a vigorar, sem qualquer limite, em 1991 (ano base de 1990), para a dedução da renda das famílias e das empresas (do 
Imposto de Renda Pessoa Jurídica - IRPJ); exceção à regra foram os gastos privados efetuados com o consumo de medicamentos para as pessoas físicas (DAIN et al., 2001). A legislação básica acerca dos benefícios tributários com saúde está contida na Lei ${ }^{\circ} 9.250 / 95$, e a norma atual que regulamenta a matéria é a RIR/99 (Regulamento do Imposto de Renda/99).

Esse processo ocorre numa conjuntura em que o Estado passa a dar tratamento ambíguo às políticas sociais na área da saúde. De um lado, a Constituição propunha a implantação de um modelo de proteção social, enraizado nas experiências do Estado de bem-estar social europeu, de molde social-democrata, que previa o financiamento público das políticas sociais via impostos e contribuições sociais. De outro, seguindo o modelo liberal norteamericano, cujas fontes de financiamento se baseiam fortemente nos tax expenditures e nos employment-benefits (MARMOR et al., 2005), estimulouse a ampliação da renúncia fiscal em saúde, permitindo a justaposição de dois modelos distintos de políticas - um identificado com o perfil político-ideológico do aparato jurídico constitucional; outro fortalecido pela adoção das idéias neoliberais na década de 90 (ver TAVARES, 1999).

Diversos estudos no campo da Saúde Coletiva dedicados ao exame do financiamento do setor saúde procuraram descrever, analisar e quantificar a renúncia fiscal (MÉDICI 1990; ANDREAZZI 1991). Esses trabalhos apontam que o incentivo econômico subjacente à renúncia acabou favorecendo a expansão da oferta hospitalar privada e, principalmente, o crescimento do mercado de planos de saúde (OCKÉ-REIS, 1995; DAIN et al., 2001).

Segundo estimativa da Secretaria da Receita Federal (Coordenação Geral de Política Tributária - COPAT), o valor da renúncia de arrecadação fiscal relativa às despesas com planos de saúde e aos desembolsos diretos com a assistência médico-hospitalar girou em torno de $\mathrm{R} \$ 2,8$ bilhões em 2005 (tabela 1). No contexto das políticas públicas, trata-se de uma magnitude expressiva, $o$ que justificaria per se aprofundar a investigação sobre as características e implicações desse incentivo governamental. Afinal, é bastante controversa a polêmica acerca da alocação desses recursos do ponto de vista da eqüidade, num quadro de custos crescentes, de um lado, e restrição fiscal de outro, na área do financiamento da atenção à saúde. 
TABELA 1

PROJEÇÃO DO GASTO TRIBUTÁRIO POR FUNÇÃO ORÇAMENTÁRIA, SEGUNDO MODALIDADE DO SUBSIDIO — 2005

(em RS milhões)

\begin{tabular}{lcc}
\hline Saúde & Valor & (\%) \\
& corrente & \\
\hline Despesas médicas - IRPF & 2.056 & 39,1 \\
Assistência médica, odontológica e farmacêutica a empregados - & & \\
(IRPJ) & 770 & 14,6 \\
Entidades sem fins lucrativos — Assisência Social & 1.376 & 26,2 \\
Medicamentos & 1.058 & 20,1 \\
Total & 5.260 & 100,00 \\
\hline
\end{tabular}

Fonte: Coordenaçâa-Geral de Política Tributária/Secretaria da Receita Federa1.

Nesse sentido, é interessante observar os resultados da discussão ocorrida no Simpósio sobre Saúde Suplementar, organizado pela Câmara dos Deputados (BRASIL/MS, 2001), uma das poucas oportunidades de debate fora do âmbito acadêmico em 2000. Destacou que o subsídio destinado às famílias para o pagamento dos planos e serviços privados de saúde era compartilhado com a sociedade, alertando políticos, técnicos e formuladores de política sobre sua natureza inequiitativa: na qualidade de gasto social, tal renúncia permitiria uma alocação diferenciada de recursos públicos, favorecendo os estratos de renda superior. Ademais - revelando o amplo leque de temas abordados nessa agenda de debate - foi sublinhado o papel que poderia ser cumprido pela renúncia fiscal na efetividade da ação tributária, ao evidenciar receitas, de outra forma, sujeitas à sonegação ${ }^{2}$ no mercado de atenção à saúde (serviços médicos prestados diretamente aos pacientes). 
Em um quadro de pobreza absoluta e desigualdade social, precisamos refletir e distinguir quais seriam os setores sociais beneficiados e prejudicados nessa relação estabelecida, por meio da renúncia de arrecadação fiscal, entre o padrão de financiamento público e o mercado de planos de saúde.

\section{A renúncia fiscal e a demanda: considerações a partir da literatura}

Em termos conceituais, Pauly (1986) acredita que a renúncia fiscal permite o aumento do número de segurados distorcendo a quantidade e o nível de cobertura de equilíbrio no mercado de planos de saúde. Por sua vez, o crescimento desse mercado demandaria serviços médico-hospitalares a tal ponto que poderia provocar aumento do nível de preços e do ritmo de crescimento de longo prazo dos serviços de saúde. Da ótica dos empregadores, de outra parte, a isenção de tributos para o pagamento de planos de saúde constitui-se em fringe benefit, onde haveria um co-financiamento por parte dos contribuintes em geral (DOWD et al., 2001).

Em particular, para a teoria microeconômica convencional - na presença de dados fidedignos - o papel desempenhado pela renúncia fiscal sobre o mercado de planos de saúde pode ser medido a partir do efeito que tal renúncia pode provocar, por exemplo, no preço médio desse mercado. Admitindo-se, assim, que a renúncia influencia o preço e o nível de oferta dos planos e da assistência médico-hospitalar, qual seria seu impacto na demanda? Qual seria a elasticidade da demanda após uma mudança da política de governo no tocante à renúncia de arrecadação fiscal?

O conceito de elasticidade é bastante usado em economia e remete à variação percentual ocorrida numa variável que está relacionada com a variação percentual ocorrida em uma outra variável:

Se o módulo da elasticidade é maior do que um, diz-se que a relação é elástica. Se esse módulo for igual a um, diz-se que a elasticidade é unitária. Se o módulo é menor do que um, diz-se que a relação é inelástica. Quanto maior (menor) a elasticidade, maior (menor) será a variação percentual, e a sensibilidade da variação da variável "X" em relação à variável "Y". [...] Um sinal positivo na elasticidade significa que as variáveis se movem no mesmo sentido, possuindo correlação positiva. Um sinal negativo implica que as variáveis se movem em sentidos opostos, possuindo correlação negativa (MARINHO, 2006, p. 2.233). 
No caso da elasticidade-preço da demanda, analisa-se a variação percentual na quantidade dividida pela variação percentual no preço (VARIAN, 2003, p. 289).

Gruber (2001) acredita que os resultados dos estudos comparativos acerca dos custos e benefícios da renúncia fiscal em saúde têm implicações controversas, considerando alguns pressupostos sobre o comportamento da demanda quando da utilização desse benefício fiscal. A despeito desse fato, ele mesmo comparou a cobertura dos planos de saúde, considerando empregadores semelhantes, prêmios diferentes e usuários de diversos estados americanos, encontrando uma elasticidade que variou entre - 0,8 a -2,9 nos Estados Unidos Isso significa que essas variáveis (prêmios de seguro e demanda) mostraram uma variação em sentido inverso. Quanto à magnitude da variação, os resultados foram controversos. No primeiro caso, para cada unidade de aumento dos prêmios dos seguros de saúde resultante da redução dos abatimentos fiscais, haveria uma redução proporcional nos usuários cobertos por planos do empregador de 0,8 pontos percentuais, refletindo uma variação menor da demanda relativa ao aumento do prêmio; isto é, que a relação foi inelástica. No segundo caso, - 2,9, a variação proporcional da demanda foi maior do que a variação proporcional do prêmio, isto é, a relação foi considerada elástica. O autor apresentou, igualmente, resultados de investigações realizadas no Canadá, cujas elasticidades da demanda em relação à oscilação dos preços foi de $-0,42$ a -0,54, após a retirada do subsídio aos empregadores, refletindo nesse caso, uma inelasticidade da demanda em relação ao preço.

Igualmente, o autor observou que um aumento na alíquota implicou redução da participação do empregador no financiamento dos planos de saúde dos empregados. Concluiu daí que as firmas empregadoras seriam mais sensíveis do que os trabalhadores ao efeito provocado pela extinção da renúncia fiscal nos preços finais dos planos. Nessa linha, em que pese Gruber e Mcknight (2003) atribuírem à elevação dos custos da assistência médica a diminuição da cobertura de planos de saúde pelos empregadores nos Estados Unidos entre 1982 e 1998, os autores admitem que uma concessão do subsídio aos empregadores não apenas aumentaria a cobertura, como também reduziria a participação financeira dos empregados no custeio total dos planos.

Essa não é, certamente, uma questão trivial para os empregados norteamericanos, que procuram garantir sua cobertura médica por meio da compra de serviços privados no mercado. Cumpre assinalar, o impacto do programa 
norte-americano Earned Income Tax Credit (EITC) ${ }^{3}$ sobre a demanda por planos de saúde dos trabalhadores de baixa renda foi bastante significativa (BAUGHMAN, 2000), considerando que tais trabalhadores passam a utilizar parte do ganho obtido com esse programa para a compra de planos de saúde, porque seu efeito na renda torna possível o pagamento dos planos oferecidos pelo empregador.

Elden \& Moeller (2000) estudaram a magnitude e a distribuição dos subsídios oferecidos pelo governo norte-americano aos usuários de planos de saúde. Segundo os autores, os subsídios eram inequiitativos, porque sua incidência variava de acordo com a taxa marginal da tributação. Isto significa dizer que quando existe uma variação no nível de renda dos usuários-contribuintes, haveria uma mudança no nível da faixa de contribuição tributária, o que, por sua vez, acabaria favorecendo as famílias dos estratos superiores de renda. Assim, um aumento da carga tributária advinda da redução ou eliminação dos subsídios afetaria esses estratos superiores. De outro ângulo, Dowd et al. (2001) analisaram os efeitos da isenção de impostos relacionados aos prêmios pagos diretamente pelos empregados, segundo a sua renda. Os resultados indicam que a demanda dos empregados era sensível (elástica) ao prêmio: a existência (ou não) da isenção de impostos altera decerto a demanda.

$\mathrm{Na}$ Europa, a renúncia fiscal com gastos privados em saúde é encontrada em diversos países, relacionada tanto a empresas quanto a pessoas físicas (COLOMBO; TAPAY, 2004), mas suas tendências parecem apontar para sua redução ou eliminação (MOSSIALOS; THOMSON 2002).

Emmerson, Frayne e Goodman (2001) analisaram um segmento populacional suis generis no Reino Unido, dada a curva exponencial dos seus custos relativos à atenção à saúde: os idosos. Os usuários de planos de saúde com mais de 60 anos de idade se beneficiavam da renúncia fiscal no imposto de renda. Em 1997, esse benefício foi interrompido. ${ }^{4} \mathrm{O}$ impacto da interrupção do benefício foi avaliado procurando-se medir a redução da cobertura nessa faixa etária, padronizada pela evolução da cobertura nos menores de 60 anos (a quem esse benefício não era permitido).

Para os indivíduos maiores de 60 anos, os resultados indicaram que a elasticidade da demanda variou $-0,7$; isto é, para cada redução de uma unidade do beneficio fiscal, houve uma queda de 0,7 unidades de indivíduos com planos de saúde, representando em termos absolutos 4.000 pessoas, num total de 500 mil participantes da pesquisa censitária. Assim, a retirada do benefício 
apresentou, nesse caso, um impacto pequeno sobre a demanda. Deve-se levar em conta o fato de essa população ter uma renda mais elevada e possuir maior propensão à utilização dos serviços e medicamentos.

$\mathrm{Na}$ Irlanda, os gastos com o sistema de atenção médica suplementar representavam 9,45\% do gasto total em saúde em 1998 e os subsídios fiscais que patrocinavam o consumo privado de seguros voluntários de saúde correspondiam a 2,5\% do gasto público em 1997. Desse modo, as estimativas da retirada do subsídio representariam um aumento de $32 \%$ no preço final dos prêmios (MOSSAIOLOS; THOMSON, 2002).

No Brasil, observou-se que os gastos privados com atenção à saúde no total dos rendimentos declarados das pessoas físicas cresceu positivamente até o patamar de 30 salários-mínimos em 1999 (SAYD, 2003). A partir daí, contudo, verifica-se redução relativa desses gastos no estrato de renda superior. Vale dizer, nessa direção, Yunes (1995) admite também uma elasticidade positiva; entretanto, a curva apresentaria taxa decrescente de evolução, ao longo dos décimos da distribuição de renda.

À primeira vista, pode-se evidenciar, com base nessa discussão, que os principais resultados foram de que o impacto da redução dos abatimentos fiscais sobre a demanda por planos de saúde seria mais acentuado em relação a firmas empregadoras do que em relação às pessoas físicas. Houve variações na resposta das firmas empregadoras a mudanças nos benefícios fiscais, sendo algumas delas no sentido da redução de sua participação no custeio de planos de saúde, mas para as pessoas físicas esse efeito, nos casos estudados, foi menor, gerando um consequiente maior comprometimento da sua renda com atenção à saúde. Desse modo, seria ingenuidade crer que a renúncia de arrecadação fiscal não fosse objeto de preocupação de entidades governamentais e dos grupos de interesse do setor saúde no Brasil. Afinal de contas, o volume dos "gastos tributários" pode afetar o montante do gasto público aplicado diretamente nos serviços de saúde.

Seu papel, entretanto, enquanto instrumento de preservação da eqüidade do financiamento da atenção à saúde deve, ao nosso ver, ser inserido numa discussão mais ampla sobre a fragilidade financeira do Estado, em face da globalização, da desigualdade social e da pobreza absoluta vistas no Brasil. 


\section{A agenda de discussão institucional}

Foram identificados três espaços relevantes de discussão sobre as políticas de saúde e a renúncia fiscal, na arena setorial dos anos 2000: o simpósio sobre Planos de Saúde, promovido pela Câmara dos Deputados, em Brasília, no ano de 2001; a XII Conferencia Nacional de Saúde, realizada em 2003; e o Fórum de Saúde Suplementar, promovido pela Agencia Nacional de Saúde Suplementar em 2003. Examinaram-se tanto os documentos preparados especificamente para subsidiar as discussões, quanto as posições oficiais de algumas entidades, bem como os relatórios finais dos eventos mencionados acima. Documentos oficiais sobre o tema foram identificados no Ministério da Fazenda. Além disso, foi incluído na análise um documento oficial do Sindicato Nacional dos Auditores Fiscais (UNAFISCO) contendo análises detalhadas da política tributária nacional, inclusive dos benefícios tributários com saúde do IRPF e IRPJ.

Existiam duas posições relevantes, a partir dos documentos analisados: uma do Ministério da Fazenda e outra no âmbito do Ministério da Saúde.

O documento do Ministério da Fazenda intitulado "Política Econômica e Reformas Estruturais" (BRASIL/MF, 2003a) apresentou as prioridades da agenda econômica do Governo Federal e analisou os impactos sociais da estrutura tributária. Nesse documento, foi sistematizado o principal objetivo da política econômica de diminuir a relação dívida pública / produto interno bruto (PIB), por meio do aumento do superávit primário, sem ampliação da carga tributária. Em particular, esse segmento do Governo Federal deixou claro sua intenção de eliminar os tributos cumulativos, reduzir as alíquotas dos impostos indiretos e revisar os benefícios e renúncias fiscais, considerados de natureza regressiva - retomando a problemática dos subsídios destinados das famílias de maior poder aquisitivo, para fins dos seus gastos com serviços sociais.

Segundo o documento,

os impostos e transferências, no Brasil, não atenuariam as desigualdades de renda, pois seriam destinados aos não-pobres. No Brasil, o grupo dos $10 \%$ mais ricos se apropria de $44 \%$ da renda total do País, enquanto os $10 \%$ mais pobres ficam com $1 \%$ da renda total. Da população economicamente ativa, cerca de $85 \%$ recebe rendimentos inferiores a cinco salários mínimos, o que corresponderia, aproximadamente, ao limite de isenção do imposto de renda de pessoas físicas (IRPF). Como conseqüência, quase toda a receita do IRPF, 
cerca de $96 \%$, é arrecadada de indivíduos que se encontram no grupo dos $10 \%$ de renda mais alta, sendo que os $1 \%$ mais ricos são responsáveis por mais de $40 \%$ de arrecadação (BRASIL/MF 2003a, p. 81).

Outro documento da mesma época, formulado pela equipe do Ministério da Fazenda, foi mais explícito quanto aos benefícios tributários referentes a gastos privados com saúde das famílias e empresas:

a possibilidade de ampliação dos recursos destinados aos brasileiros mais pobres e de fornecer uma verdadeira rede de proteção social capaz de amparar a população mais vulnerável, depende, de forma decisiva, da realização de reformas estruturais que reduzam os privilégios concedidos pelo atual sistema - tanto por meio de gastos diretos quanto através de renúncias fiscais - a grupos de renda mais alta [...]. Na área da saúde, cabem, ainda, reflexões sobre as renúncias tributárias em saúde (pessoa física e jurídica), auferidas por segmentos sociais de maior renda (BRASIL/MF, 2003b, p. 11-31).

Paralelamente, em suas deliberações sobre financiamento do setor saúde, o relatório final da XII Conferência Nacional de Saúde (BRASIL/MS, 2003) apresentou uma proposta que visa a eliminar, explicitamente, a renúncia fiscal dos gastos privados com planos de saúde e assistência médico-hospitalar. No seu ponto 27, aprovou-se a política de

suspender os subsídios oriundos da dedução de Imposto de Renda para gastos com planos e seguros de saúde, revertendo os valores correspondentes arrecadados para a constituição de um fundo nacional voltado para o financiamento de ações emergenciais em saúde e de atenção básica.

Em um primeiro exame, conforme o quadro descrito acima, tanto o Ministério da Fazenda quanto a Conferência Nacional de Saúde parecem querer corrigir a suposta distorção causada pela renúncia de arrecadação fiscal, patrocinada aos indivíduos e empresas que declaram imposto de renda. O mesmo benefício não se aplica a camadas sociais que, embora efetuem gastos privados com saúde, não têm acesso a recursos financeiros equivalentes à magnitude da renúncia fiscal por estarem fora do mercado formal de trabalho ou não alcançarem uma renda mínima legalmente considerada tributável. Por exemplo, no ano-base de 2004, o limite de isenção equivalia a uma renda anual do contribuinte (e seus dependentes, acaso existentes) de $\mathrm{R} \$ 12.696,00$, o que representou, na época, cerca de quatro salários-mínimos. Uma família na faixa 
de três salários-mínimos pode ter um gasto bruto com saúde equivalente, porém não teria uma redução do gasto.

No interior das instituições, vale ressaltar, finalmente que não é consensual a conceituação acerca do abatimento com saúde do IRPF como gasto ou beneficio tributário. De acordo com documento elaborado pela assessoria técnica do UNAFISCO (2003), o Ministério da Fazenda classificaria, de forma equivocada, as despesas com dependentes, educação e saúde do IRPF (despesas para um mínimo existencial) como beneficio tributário (renuncia fiscal). Essas despesas não representariam um aumento da disponibilidade econômica do contribuinte, já que substituem despesas com serviços não garantidos na prática pelo Estado:

\footnotetext{
não se pode renunciar a uma renda que não existe, pois o rendimento bruto não representa a capacidade contributiva do contribuinte. Esta só começa após a dedução dos gastos necessários a aquisição e manutenção da renda e do patrimônio, assim como do mínimo indispensável a uma existência digna para o contribuinte e sua família (UNAFISCO, 2003, p. 7).
}

Considerando os marcos da política econômica do Governo Federal e o montante dos recursos financeiros associados à renúncia, veremos a seguir quais seriam os possíveis conflitos de interesse envolvidos nessa arena. Em particular, problematizar o provável tratamento que o Ministério da Fazenda adotaria no caso do surgimento de recursos extras originários da eliminação dos gastos tributários decorrentes das despesas privadas com planos de saúde e com os desembolsos diretos efetuados com médicos, exames e hospitais. Seriam eles reaplicados nos programas voltados à atenção básica em saúde, de acordo com a resolução da XII Conferência Nacional de Saúde?

Será oportuno agora esclarecer como o conceito de eqüidade tangencia toda essa discussão relativa à renúncia de arrecadação fiscal na área da saúde, no contexto do debate do financiamento setorial do SUS. Quem sabe assim seja mais fácil compreender os diferentes propósitos das políticas apresentadas pelo Ministério da Fazenda e pela Conferência Nacional de Saúde. Como nos chamou atenção Pereira, o significado de eqüidade na saúde "depende, de forma crucial, da maneira como se define o conceito de justiça social, e que este, por sua vez, depende de juízos de valor ou pontos de vista da sociedade, tal como articulados por indivíduos, grupos ou governos" (PEREIRA, 1990, p. 401). 


\section{Breves comentários acerca da questão da eqüidade}

Segundo Ugá \& Santos (2005), o conceito de eqüidade no financiamento da saúde estaria relacionado à distribuição dos gastos das famílias em saúde em proporção aos seus proventos: a incidência é progressiva caso o ônus cresça com a classe de rendimentos, e regressiva no caso inverso.

Adotando uma perspectiva normativa, de outra parte, organismos financeiros internacionais vêm-se apoiando no conceito de eqüidade para justificar a focalização dos gastos para aqueles grupos sociais que não têm condições de acesso aos serviços de saúde por meio das ações de mercado (WORLD BANK, 1987).

Em relação ao último aspecto, vale dizer que o SUS pressupõe um modelo de proteção social que pode superar essa aparente contradição entre políticas universais e focais, por meio da combinação de programas seletivos capazes de promover o acesso de grupos mais vulneráveis e ao mesmo tempo inseri-los no interior do sistema universal de saúde (FLEURY, 2000). No entanto, o SUS vive um processo tenso, com avanços e recuos, diante dos conflitos presentes no financiamento das políticas públicas de saúde. Sem dúvida, a aplicação da eqüidade nos mecanismos de financiamento do SUS seria uma peça-chave fundamental para a própria materialização dessa diretriz constitucional.

É importante, porém, constatar que se alegam questões ligadas à equidade no financiamento como instrumento de priorização na alocação de recursos públicos de saúde de forma problemática. Numa conjuntura de ajuste de recursos públicos para a saúde que caracteriza, no essencial, os anos pós90, isso pode significar a implementação de mecanismos de racionamento que punem determinadas camadas da população, quando as decisões pertinentes ao alcance de uma eqüidade não-excludente se encontram fora do âmbito de resolução do setor.

Quando refletimos sobre a hierarquização das prioridades de alocação dos recursos do governo nas ações e serviços de saúde, num quadro agravado pela restrição fiscal, aparece o debate em torno da renúncia de arrecadação fiscal, à luz da eqüidade do financiamento. Alguns analistas consideram regressiva a renúncia fiscal com gastos privados em saúde no Brasil, porque favoreceria os grupos com maior capacidade de gasto, "gerando maior necessidade de recursos públicos para a saúde” (UGÁ; SANTOS, 2005, p. 74). Isso também já foi descrito nos trabalhos internacionais aqui examinados. 
Essas características da renúncia fiscal com atenção privada à saúde não são peculiares ao caso brasileiro (SHEILS; HOGAN 1999), e apontam um aspecto de ordem estrutural desse modelo de subsídio público para a saúde. Em outras palavras, à primeira vista, o Estado, por meio do padrão de financiamento público, na predominância de sistemas privados, favoreceria as condições de rentabilidade dos planos e serviços de saúde, resolvendo em parte a necessidade da remarcação sistemática de preços (BAYER; LEIS, 1986).

Do ponto de vista do gasto público per capita em saúde, parece consensual admitir - considerando que uma unidade do gasto tributário é igual a uma unidade do gasto público em saúde - que os indivíduos que abatem seus gastos no imposto de renda receberiam, em termos per capita, mais recursos do Estado. Decorreria daí, em termos econômicos, o caráter inequiitativo do gasto tributário. Esse gasto tributário, entretanto, não representa a totalidade do gasto em saúde dos contribuintes, apenas uma parcela. Assim, se levarmos em conta os resultados das simulações de elasticidade apresentadas no início deste trabalho, é plausível supor que uma política voltada à redução ou eliminação desse subsídio não afetaria substancialmente a demanda das famílias por planos de saúde, embora possa afetar a demanda dos planos empresariais.

Para as famílias, as necessidades de saúde estão presentes nas decisões acerca dos gastos, mas para as empresas, cálculos mais racionais relativos aos custos e benefícios associados às coberturas de riscos de saúde são possíveis. Por um lado, considerando que esses gastos tributários com saúde sejam inteiramente alocados ao SUS, sem redução concomitante dos níveis atuais de gasto público, isso poderia acomodar eventuais pressões imediatas sobre o acesso e utilização do SUS, cujas fontes de financiamento permanecem instáveis (RIBEIRO et al., 2005). Por outro, extrapolando a dimensão setorial do debate, isso implicaria maiores despesas com saúde das famílias que se encontram acima do limite de isenção (acima de cerca de quatro salários-mínimos). Podese supor que as parcelas mais afetadas sejam aquelas abaixo do patamar aproximado de 30 salários-mínimos, onde o percentual do gasto em saúde relativo à renda é mais elevado (SAYD, 2003).

De fato houve, no Brasil, uma considerável queda do rendimento médio das famílias (POCHMANN, 2001), contribuindo para a redução do crescimento do mercado de planos na década de 90, sabendo-se que a cobertura dos planos de saúde tem relação direta tanto com a renda quanto com o emprego por ramo de atividade das empresas (ANDREAZZI; KORNIS, 2003). 
Sem entrar no mérito se os gastos privados das famílias constituem ou não uma "preferência do consumidor", pois em alguma medida tais famílias são compelidas a utilizar o mercado privado de serviços de saúde, dados o acesso precário e a qualidade duvidosa de certos procedimentos oferecidos pelo SUS, surge um dilema para os formuladores de política. Da ótica setorial, parece razoável defender a idéia da redução e ou eliminação da renúncia fiscal visando a atender ao princípio da eqüidade no financiamento da saúde, dado que o sistema teoricamente deveria cobrir as necessidades de saúde de todos os cidadãos. No entanto, da ótica macroeconômica, isso significaria punir apenas os setores de renda média, que estão já sendo desfavorecidos pela política econômica (POCHMANN, 2001). Além do mais, os compromissos atuais do Governo Federal com a consecução do superávit primário e das metas de inflação, de uma parte, não asseguram a priori que recursos equivalentes aos gastos tributários atuais com saúde sejam dirigidos para os grupos mais vulneráveis. De outra parte, esses compromissos impedem a expansão dos recursos financeiros necessários para se consolidar o caráter único do SUS incorporando toda a população a um cuidado integral. Para ilustrar, cabe lembrar que a recente polêmica em torno da aplicação dos recursos provenientes da Contribuição Provisória sobre Movimentação Financeira (CPMF) residiu no fato de que o aumento da arrecadação promovida pela CPMF não resultou em aportes adicionais para a saúde, porque houve, a rigor, uma substituição das fontes prévias do financiamento público da atenção à saúde (OCKÉ-REIS; RIBEIRO; PIOLA, 2001).

Em suma, boa parte da arrecadação com tributos é destinada ao pagamento da dívida pública, cujos encargos são sistematicamente retroalimentados pelas elevadas taxas de juros, dada a subordinação do modelo econômico atual aos mecanismos de especulação financeira (BRESSERPEREIRA, 2003, p. 103). Esse autor, comentando os gastos sociais do Estado, afirma haver uma "distorção maior em relação ao gasto total do Estado é aquela com os juros, resultado não apenas de uma divida pública alta, mas principalmente de uma taxa de juros básica absurda". De forma marcante, observa-se a presença de um esquema de desvio das riquezas geradas no país para a acumulação financeira, supondo-se que "a correlação entre carga tributária e aumento do superávit primário é por demais transparente para demonstrar que o arrocho fiscal tem significado uma transferência de recursos para o setor financeiro, tendo, aliás, parcela significativa sido subtraída da renda do trabalho" (PREFEITURA DE SÃO PAULO, 2003, p. 73). 
A seguir, cabe problematizar a consistência de uma política de redução ou eliminação desse subsídio fiscal por parte do Ministério da Fazenda com o objetivo de reverter tal beneficio para as parcelas mais pobres ou "mais" doentes da população, sob o pretexto de garantir a eqüidade do financiamento do SUS. Em especial, enfatizando as possíveis perdas e ganhos da retirada desse incentivo governamental.

\section{Os conflitos de interesse}

Quem se beneficiaria com a renúncia de arrecadação fiscal relativa aos gastos privados com planos de saúde e aos desembolsos diretos com assistência médico-hospitalar?

Antes de responder a essa pergunta, seria importante dimensionar o tamanho dessa questão. Para as pessoas físicas, estamos falando de recursos da ordem de R \$ 11,78 per capita no ano de 1998 (SAYD, 2003). A se manter o quadro verificado em 2005 (tabela 1), os abatimentos de pessoas jurídicas significariam cerca de 1/3 das pessoas físicas. Para efeito de comparação dos benefícios tributários com saúde com respeito aos gastos públicos com saúde, tomamos o trabalho de Ugá \& Santos (2005), que estimam um gasto público total em saúde de $\mathrm{R} \$ 50,5$ bilhões de reais em 2002 ( $\mathrm{R} \$$ 67,39 bilhões a preços de 2005, corrigidos pelo IPCA/IBGE). A estimativa da magnitude do benefício tributário vis-à-vis o gasto público estaria na ordem de 4,2\%. Mas essa ordem de grandeza, de outra parte, não pode ser considerada tão desprezível quando se observa o volume de recursos dos programas médico-assistencias, organizados no âmbito do Ministério da Saúde (ver OCKÉ-REIS et al., 2006).

No caso da imposição de um teto de renda para permitir o dispositivo da renúncia de arrecadação fiscal, se fosse usado um corte na classe de rendimentos das famílias com renda superior a 30 salários mínimos mensais, veríamos que os valores correspondentes à renúncia nessa faixa de salários representavam, em 1998, 9,1\% da renúncia total com saúde, ou seja, $\mathrm{R} \$ 1,07$ per capita anual (SAYD, 2003). A rigor, os grupos sociais que utilizam o setor privado e deduzem seus respectivos gastos na declaração do imposto de renda da pessoa física e jurídica têm-se beneficiado desse incentivo governamental. No entanto, é importante constatar que o peso dos gastos com saúde das famílias é maior nos estratos inferiores e médios de renda, isto é, abaixo de 30 saláriosmínimos (SAYD, 2003; OCKÉ-REIS; GAIGER; ANDREAZZI, 2003) 
Considerando a hipótese da manutenção de um nível de gastos privados com saúde mesmo se eliminando o benefício tributário, em função das dificuldades não-resolvíveis em médio prazo do SUS, as famílias que serão proporcionalmente mais afetadas serão aquelas de rendas médias e médias baixas, e não aquelas de rendas mais elevadas.

Raciocínio análogo pode ser feito em relação às empresas. Os empregadores se beneficiam dos incentivos patrocinados pela renúncia fiscal dos gastos destinados aos seus empregados e executivos. Em média, 58\% dos empregadores gastam mais de $7 \%$ da folha de pagamento com planos de saúde (TOWERS, 2002). Em uma situação desvantajosa, num primeiro exame, se encontram as empresas que atuam em mercados competitivos, menos intensivas em capital e onde o peso da força de trabalho é mais significativo, sem a possibilidade de abater os gastos com planos de saúde dos seus funcionários.

Em relação aos grandes planos de saúde, a eliminação da renúncia fiscal poderá, provavelmente, acarretar em perda de receitas, em função da retração dos usuários afiliados de contratos coletivos e individuais. Finalmente, parcela ignorada do mercado de serviços de atenção à saúde financiado pelo desembolso direto das famílias poderia, ocasionalmente, se beneficiar marginalmente com a "perda" de controle da Secretaria da Receita Federal sobre as origens das suas receitas, dado o fim dos registros burocráticos que permitiriam checar as notas fiscais relativas às prestações dos serviços médicos e hospitalares. Esse seria um argumento, de ordem fiscal, a favor da manutenção dos gastos tributários, no que se refere à efetividade da renúncia enquanto estratégia de combate à sonegação fiscal dos prestadores privados de saúde. Esse segmento exige uma fiscalização ativa, que muitas vezes se torna-se problemática: os profissionais liberais e hospitais estão espalhados em todo o território nacional, diferentes, por exemplo, dos planos de saúde, que estão concentrados nas regiões Sudeste e Sul com presença marcante nas regiões metropolitanas do país (ANDREAZZI; KORNIS, 2003).

Resumindo, a retirada do subsídio implicaria menor informação sobre a base da receita dos prestadores privados de saúde para finalidades fiscais, cujos efeitos sobre o conjunto da arrecadação de tributos não são quantificáveis. Nesse cenário, tirando a questão específica relativa à sonegação fiscal dos prestadores, o Ministério da Fazenda não teria interesse em manter os subsídios destinados às classes de maior rendimento, alegando um princípio distributivo, mas quem sabe defendendo interesses de alcance de metas de superávit primário 
das contas públicas. Contudo, existem contradições políticas que desmotivariam o governo a tomar essa decisão no bojo do ciclo político-eleitoral, em especial a ausência de mecanismos compensatórios para as classes médias - segmento importante na formação da opinião pública - no contexto de baixas taxas de crescimento econômico e da renda per capita (PREFEITURA DA CIDADE DE SÃO PAULO, 2003).

A redução ou mesmo eliminação da renúncia não deve vir acompanhada de uma elevação do gasto público com saúde que compensasse o maior encargo assumido por famílias e empresas, uma vez que isso seria da esfera de mudanças da política macroeconômica do país. Desse modo, de um lado, a restrição ou definição de um teto limitando a renúncia relativa aos gastos com planos de saúde, bem como com assistência médico-hospitalar - de acordo com a renda do indivíduo e de acordo com o faturamento ou lucro líquido da empresa - não significaria, necessariamente, a aplicação de recursos públicos adicionais na área da saúde.

\section{Considerações finais}

Esperamos ter alcançado o objetivo proposto de subsidiar a discussão e formulação de uma política pública no setor no tocante à renúncia de arrecadação fiscal. Para aprofundar a reflexão desenvolvida neste trabalho seria importante, entretanto, superar algumas de suas lacunas, a partir da revisão de temas já explorados ou pouco explorados na literatura no tocante ao assunto.

Citamos, por exemplo, o próprio conceito de gasto tributário (tax expenditure), estudos empíricos que permitissem a mensuração mais precisa do gasto público federal em saúde que incluísse os benefícios tributários, a análise de incidência do gasto público federal em saúde, os impactos sobre o mix público / privado (e sobre o macrossetor saúde) com o fim da renúncia fiscal; a discussão dos modelos de financiamento (subsídios à demanda) e finalmente a determinação de empregos/salários e rotatividade do fator trabalho (por meio desse fringe benefit).

Da ótica do orçamento público federal, a introdução de uma política com a finalidade de reduzir o caráter ineqüitativo da renúncia de arrecadação fiscal teria efeito questionável sobre a iniqüidade do financiamento setorial, pois nada garante que o Ministério da Fazenda vai aplicar tais recursos na área da saúde, haja vista a experiência da CPMF. Além do mais, em que pese a renúncia incidir sobre as camadas de renda média - que vivem, sobretudo da renda do 
trabalho (MEDEIROS, 2004) - outros recursos da União poderiam ser remanejados para atender à assistência médica dos mais pobres, já que atualmente $65 \%$ do orçamento são destinados ao pagamento do estoque e dos encargos financeiros da dívida pública (PREFEITURA DA CIDADE DE SÃO PAULO, 2003).

Caso se queira fortalecer o SUS, a escassez de recursos públicos problematiza per se a permanência da renúncia fiscal, que é nitidamente inequiitativa da ótica da distribuição do gasto público federal em saúde. A permanecer tal renúncia, podia-se ao menos discutir a possibilidade de ela ser alocada para a clientela de maior risco (os idosos), para os procedimentos de alto custo (tratamentos cirúrgicos intensivos), justamente os segmentos mais estigmatizados pela seleção de risco praticada pelas operadoras de planos de saúde, indo ao encontro da proposta da Conferência Nacional de Saúde. Ou ainda, de outro ângulo, que ela funcionasse como mecanismo indutor para fomentar um programa de reforma institucional do mercado de planos de saúde em defesa do consumidor, da concorrência regulada e do interesse público (OCKÉ-REIS, 2005, p. 316).

O efeito da renúncia de arrecadação fiscal sobre a dinâmica do mercado de serviços de saúde parece não ser trivial, embora não tenham sido mensurados minuciosamente. O acesso universal aos serviços de saúde prestados pelo SUS é interditado pela combinação perversa de um conjunto de fatores, entre eles, corrupção da máquina pública, gestão ineficiente, distorções orçamentárias e pelo baixo gasto público per capita em saúde.

No caso brasileiro, então, em que pesem possíveis ganhos incrementais no orçamento, conclui-se que a eliminação ou redução da renúncia fiscal com gastos privados em saúde, desacompanhada de outras medidas de política econômica que promovam a eqüidade do ponto de vista das capacidades de participação nas riquezas produzidas no país implicaria, marcadamente, ônus tributário para as classes de renda média e média baixa, e as médias empresas, restando dúvidas se recursos financeiros adicionais cheguem, de fato, aos mais pobres.

\section{Referências}

ALMEIDA, C. O mercado privado de serviços de saúde no Brasil: panorama atual e tendências da assistência médica suplementar. Brasília: IPEA, 1998 (Textos para Discussão n. 599). 
ANDREAZZI, M. F. S.; KORNIS, G. E. M. Papel das reformas dos anos 90 na demanda por seguros privados de saúde no Brasil: consensos e dissensos. Cad. Saúde Coletiva. Rio de Janeiro, v. 11, n. 2, p. 201-229, 2003.

ANDREAZZI, M. F. S. O seguro saúde privado no Brasil. Dissertação (Mestrado em Ciências) - Escola Nacional de Saúde Pública, Fundação Oswaldo Cruz, Rio de Janeiro, 1991.

BAUGHMAN, R. Evaluating the impact of the earned income tax credit on health insurance coverage for low-income Workers. Paper presented at Yale University Robert Wood Johnson Health Policy Program Seminar, 2002.

BAYER, G. F.; LEIS, H. Saúde enquanto questão politicamente intermediada. Serviço Social e Sociedade, n. 22, p. 103-125, 1986.

BIDERMAN, C.; ARVATE, P. Economia do setor público no Brasil. São Paulo: Elsevier, 2005.

BRASIL. MINISTÉRIO DA FAZENDA. Política Econômica e Reformas Estruturais. Brasília, 2003a. Disponível em: <http://:www.fazenda.gov.br> Acesso em: 20 jun 2005.

BRASIL. MINISTÉRIO DA FAZENDA. Secretaria de Política Econômica. Gasto Social do governo central: 2001 e 2002. Rio de Janeiro: Econômica, v. 5, n. 1, p. 9-69, 2003b.

BRASIL. MINISTÉRIO DA SAÚDE. Simpósio Regulamentação dos Planos de Saúde. Brasília, 2001.

BRASIL. MINISTÉRIO DA SAÚDE. Relatório Final da XII Conferência Nacional de Saúde. Brasília, 2003. Disponível em: http:// www.conselho.saude.br. Acesso em: 15 jul. 2005.

BRESSER-PEREIRA, L. C. Economia política do gasto social no Brasil desde 1980/85. Rio de Janeiro: Econômica, v. 5, n. 1, p. 101-108, 2003.

COMISSÃO ECONÔMICA PARA A AMÉRICA LATINA. Casos de êxito na política fiscal brasileira, out. 1991 (Série Política Fiscal n. 15).

COLOMBO, F.; TAPAY, N. Private health insurance in OECD countries: The benefits and costs for individuals and health systems. Paris: OECD, 2004 (OECD Health Working Papers, n. 15). 
DAIN, S. et al. Avaliação dos impactos da reforma tributária sobre o financiamento da saúde In: NEGRI, B.; GIOVANNI, G. (Orgs.). Brasil: radiografia da saúde. Brasília: Ministério da Saúde, 2001. p. 233-288.

DOWD, B. et al. The effect of tax-exempt out-of-pocket premiums on health plan choice. National Tax Journal. Washington, DC, v. 54, n. 4, p. 741-756, Dec 2001.

EMMERSON, C.; FRAYNE, C.; GOODMAN, A. Should private medical insurance be subsidized? Health Care United Kingdom, v. 51, n. 4, p. 49-65, 2001.

FLEURY, S. M. T. Reshaping health care systems in Latin America: Toward fairness? In: FLEURY, S. M. T.; BELMARTINO, S.; BARIS, E. (Eds.). Reshaping health care in Latin America: a comparative analysis of health care reform in Argentina, Brazil, and Mexico. Canada: International Development Research Centre Press, 2000. p. 225-262.

GRUBER, J. Taxes and health insurance. Cambridge, MA: National Bureau on Economic Research., 2001 (Working Paper 8657). Disponível em: http:// www.nber.org/papers/w8657. Acesso em: 01 jun. 2006.

GRUBER, J.; MCKNIGHT, R. Why did employee health insurance contributions rise? J. Health Econ. v. 22, p. 1.085-1.104, 2003.

MARINHO, A Um estudo sobre as filas para transplantes no Sistema Único de Saúde brasileiro. Cad. Saúde Pública. Rio de Janeiro, v. 22, n. 10, p. 2.2292.239 , out 2006 .

MARMOR, T.; FREEMAN, R.; OKMA, K. Comparative perspectives and policy learning in the world of health care. Journal of Comparative Policy Analysis: research and practice, v. 7, n. 4, p. 331-348, 2005.

MEDEIROS, M. As fontes de rendimentos dos ricos no Brasil. Brasília: Instituto de Pesquisas Econômicas Aplicadas, 2004 (Textos para Discussão n. 1.014).

MÉDICI, A. C. Incentivos governamentais ao setor privado no Brasil. Rio de Janeiro: ENCE/IBGE, 1990 (Relatórios Técnicos n. 1).

MOSSIALOS, E.; THOMSON, S. M. S. Voluntary health insurance in the European Union: a critical assessment. Int. J. Health Services. Baltimore, v. 32, n. 1, p. 19-88, 2002. 
OCKÉ-REIS, C. O. A reforma institucional do mercado de planos de saúde: uma proposta para criação de benchmarks. In: PIOLA, S. F. (Org.). Prêmio em Economia da Saúde. I Prêmio Nacional - 2004: Coletânea Premiada, Brasília: IPEA, 2005. p. 289-324.

- O setor privado em saúde no Brasil: os limites da autonomia. Dissertação (Mestrado em Saúde Coletiva) - Instituto de Medicina Social, Universidade do Estado do Rio de Janeiro, Rio de Janeiro, 1995.

OCKÉ-REIS, C. O.; ANDREAZZI, M. F. S.; SILVEIRA, F. G. O mercado de planos de saúde: uma criação do Estado? ?Revista de Economia Contemporânea. Rio de Janeiro, v. 10, n. 1, p. 157-185, 2006.

OCKÉ-REIS, C. O.; RIBEIRO, J. A. C.; PIOLA, S. F. Financiamento das políticas sociais nos anos 1990: o caso do Ministério da Saúde. Brasília: IPEA, 2001 (Textos para Discussão n. 802).

PAULY, M. V. Taxation, health insurance, and market failure in the medical economy. Journal of Economic Literature, v. 24, n. 2, p. 629-675, June 1986.

PEREIRA, J. Justiça social no domínio da saúde. Cad. Saúde Pública. Rio de Janeiro, v. 6, n. 4, p. 400-421, out.-dez. 1990.

PIOLA, S. F.; BIASOTO JUNIOR, G. Financiamento do SUS nos anos 90 In: NEGRI, B.; GIOVANNI, G. (Org.). Brasil: radiografia da saúde. Brasília: Ministério da Saúde, 2001. p. 219-232.

POCHMANN, M. A década dos mitos. São Paulo: Contexto, 2001.

PREFEITURA DA CIDADE DE SÃO PAULO. Desigualdade de renda e gastos sociais no Brasil: algumas evidências para debate. Econômica. Rio de Janeiro, v. 5, n. 1, p. 71-82, 2003.

RIBEIRO, J. A.; PIOLA, S. F.; SERVO, L. M. As novas configurações de antigos problemas: financiamento e gasto com ações e serviços públicos de saúde no Brasil. Trabalho apresentado na II Jornada de Economia da Saúde, Belo Horizonte, 2005 (mimeo).

SANDRONI, P. Novo Dicionário de Economia. São Paulo: Best Seller, 1999. SAYD, P. D. Renúncia Fiscal e eqüidade na distribuição de recursos para a saúde. Dissertação (Mestrado em Saúde Coletiva) - Escola Nacional de Saúde Pública, Fundação Oswaldo Cruz, 2003. 
SELDEN, T. M.; MOELLER, J. F. Estimates of the tax subsidy for employmentrelated health insurance. National Tax Journal. Washington, DC, v. 53, n. 4, p. 877-887, Dec 2000.

SHEILS, J.; HOGAN, P. Cost of tax-exempt health benefits in 1998. Health Affairs, v. 18, n. 2, p. 176-181, 1999.

TAVARES, L. T. S. R. Políticas e ajuste e reformas da seguridade social na América Latina In: ANDREAZZI, M. F. S.; TURA, L. F. R. (Org.). Financiamento e gestão do setor saúde: novos modelos. Rio de Janeiro: Anna Néry, 1999. p. 25-44.

THE WORLD BANK. Financing Health Services in Developing Countries: an agenda for reform. Washington, DC: WHO, 1987.

TOWERS, P. Benefício saúde. Como gerenciar custos. Update, n. 27, mar. 2002. UGA, M.A.D.; SANTOS, I. S. Uma análise da equidade do financiamento do sistema de saúde brasileiro. Relatório de Pesquisa. Projeto Economia da Saúde. Cooperação Técnica Brasil - Reino Unido, 2005. Disponível em: < (http:// www.opas.org.br/observatorio/arquivos/Destaque99.pdf. Acesso em: 12 mar 2005.

UNAFISCO SINDICAL. O imposto de renda na reforma tributária. Fundamentos da Campanha Imposto de Renda com Justiça. Brasília: Ministério da Fazenda, 2003.

VARIAN, H. R. Microeconomia: princípios básicos. Rio de Janeiro: Elsevier, 2003.

VILLELA, L. A. Gastos tributários e justiça social: o caso do IRPF no Brasil. Dissertação (Mestrado em Economia) - Departamento de Economia, Pontifícia Universidade Católica do Rio de Janeiro, 1981.

YUNES, R. Demanda e demanda em saúde. In: PIOLA, S. F.; VIANNA, S. M. Economia da saúde: conceito e contribuição para a gestão da saúde. Brasília: IPEA, 1995. p. 99-122.

\section{NOTAS}

- Médica, Doutora em Saúde Coletiva (IMS-UERJ); professora adjunta no Departamento de Medicina Preventiva e pesquisadora do Núcleo de Estudos de Saúde Coletiva da UFRJ. Endereço eletrônico: siliansky@iesc.ufrj.br. 
- Economista e Doutor em Saúde Coletiva IMS/UERJ; pesquisador do IPEA e assessor da presidência ANS. Endereços eletrônicos: carlos.octavio@ipea.gov.br e carlos.octavio@ ans.gov.br. ${ }^{1}$ Este trabalho foi realizado com apoio do CNPq, Edital 37/2004, Processo 403.458/2004-8. Os autores agradecem ao parecerista anônimo pelos comentários que dotaram o texto de clareza e rigor conceitual.

${ }^{2}$ De acordo com Sandroni (1999), sonegação fiscal se refere ao uso de meios ilegais para diminuir ou evitar o pagamento de impostos, taxas, etc.

${ }^{3}$ A título de esclarecimento, o EICT é semelhante a alguns programas sociais brasileiros (bolsaescola, cheque-cidadão etc.).

4 "The current government has abolished all subsidies for those taking out PMI (private medical insurance). The abolition of tax relief to the over-60s, announced in the July 1997 Budget..."(EMMERSON, FRAYNE \& GOODMAN, 2001, p. 55).

\section{ABSTRACT}

Tax expenditures on health care: contributions toward a public policy agenda

The work discusses the tax incentives with private medical expenses to families and workers in Brazil. The estimate presented by the Federal Fiscal Authority is $\mathrm{R} \$ 2,8$ billions in 2005. Initially, a review of concepts about the matter is performed that stressed the lack of consensus in the academic community, about the meaning of tax expenditures. It discussed, also, the relations between this fiscal policy and demand to private health insurance. After, the article presents the results of a documental research concerning political positions of relevant Brazilian social actors found in the 2000's. The discussion pointed to problems of equity and conflicts of interests that are involved with the changes in the rules that discipline these incentives.

Key words: Tax expenditures on health care; Health financing; Political economy of health; Health policy 